\title{
Efficacy of risk score dependent antiemetic regimens in reduction of post operative nausea and vomiting
}

\author{
Renuka R. ${ }^{1, *}$, Radhika D. Dhandal ${ }^{2}$ \\ ${ }^{1}$ Assistant Professor, ${ }^{2}$ Professor, Dept. of Anaesthesia, ${ }^{\mathbf{1}}$ Sapthagiri Institute of Medical Sciences, Mangalore, Karnataka, ${ }^{2}$ St. \\ John's Medical College, Bengaluru, Karnataka, India
}

*Corresponding Author:

Email: drmadhumitha9@rediffmail.com

Received: $27^{\text {th }}$ October, 2017

Accepted: $07^{\text {th }}$ December, 2017

\begin{abstract}
Postoperative nausea and vomiting (PONV) is a common complication after anaesthesia. Although self limiting and non fatal, it can cause significant morbidity and delay discharge. The intention of doing this study was, to evaluate the accuracy of three risk scores in predicting PONV and to evaluate the efficacy of different therapeutic regimens based on the risk score in the reduction of PONV.

Materials and Methods: In this prospective, randomized, double blinded study, 180 patients between 18-60 years age group, belonging to ASA 1 and ASA 2 categories coming for elective surgeries under general anaesthesia of 1-4hrs duration irrespective of the type of surgery were scored preoperatively for postoperative nausea and vomiting using APFEL, KOIVURANTA, PALAZZO and EVANS scoring systems into low risk and high risk groups. Low risk group (i.e., Group O) consisting of 60 patients - inj. ondansetron 4mg was given intravenously 30 minutes before administration of reversal agent. High risk group was further categorized into Group M and Group D consisting of 60 patients each, based on the intervention to assess the efficacy of the drugs used in these two groups. Group M patient received inj.ondansetron 4mg+inj.metoclopramide 10mg intravenously (IV) 30 minutes before administration of reversal agent. Group D patient received inj. dexamethasone $4 \mathrm{mg}$ IV at induction and inj.ondansetron 4mg IV 30 minutes before administration of reversal agent. After the procedure, patients were observed for any retching, nausea or vomiting in postanaesthesia care unit and up to 24 hours. Rescue treatment from a drug of different pharmacological group was administered if required.

Results: Area under the curve (AUC) and the corresponding 95\% confidence intervals for the scores drawn from Receiver operator characteristic (ROC) curves were: Apfel: 0.6154 (0.50470-0.72618); Koivuranta: 0.6154 (0.50470-0.72618); Palazzo \& Evans: 0.6443 (0.54096-0.74764). And, a complete response of 71.67\% was observed in Group O, 76.67\% in Group M and 90\% in Group D. Thus we concluded that, all the three scores had moderate accuracy in predicting the risk of PONV and ondansetrondexamethasone combination was found to be superior to ondansetron- metoclopramide combination in high risk patients.
\end{abstract}

Keywords: General anaesthesia, Scoring systems, Ondansetron, Dexamethasone, Metoclopromide.

\section{Introduction}

Postoperative nausea and vomiting (PONV) is a common complication occuring after both general and regional anaesthesia. Despite new advances in anaesthesia and the introduction of a new class of antiemetics, PONV is one of the most common complaint in postoperative patients. The incidence is reported to be in the range of $20-30 \%^{1}$ and is known to rise up to $80 \%$ or more in high risk patient groups. Persistence of nausea and vomiting postoperatively can result in dehydration, electrolyte imbalance and delayed discharge especially in ambulatory surgery. Persistent retching and vomiting can cause tension in suture lines, venous hypertension, bleeding under skin flaps and increased risk of pulmonary aspiration of vomitus if airway reflexes are depressed from the residual effects of anaesthetic and analgesic drugs. ${ }^{1-3}$ Because of the limited efficacy of routine antiemetic prophylaxis in unselected patients it is more reasonable to manage PONV according to the individual risk of each patient. Thus, the knowledge of scoring systems will enable us to identify risk patients better, further reduce the incidence of PONV and increases the safety, cost-effectiveness of
PONV prophylaxis. Hence, we decided to compare the efficacy of 3 different scoring systems namely APFEL, KOIVURANTA, PALAZZO and EVANS in predicting PONV and to compare the efficacy of different therapeutic regimens based on the risk score in reduction of postoperative nausea and vomiting.

A number of groups have sought not only to identify independent PONV risk factors but to develop formulae quantifying a given patients likelihood of suffering nausea, emetic events or both. ${ }^{4-9}$ They have introduced 8 major PONV risk scoring systems. ${ }^{4,9}$ These formulae preponderantly include patient related factors and only 2 formulae include both surgery related and anaesthesia related factors. ${ }^{4,11}$ No scoring system yet has emerged as a "gold standard" based on accuracy. Apfel etal ${ }^{8}$ and Koivuranta etal $^{5}$ created a simplified scoring systems removing weighting of predictions and incorporating only 4 and 5 risk factors, respectively. Eberhart etal ${ }^{10}$ created a 4- item simplified scoring system for children. Vanden Bosch etal ${ }^{11}$ have taken a different approach that is categorized as "semi-simplification". Their scoring system also omits constants or co-efficients, and it contains only 5 items. However, rather than scoring each 
item 0 or 1 ("no" or "yes"), the system assigns different point values to particular alternative variables for each item, so that a nomogram is required to use the system. Eberhart etal ${ }^{10}$ and Vanden Bosch et $\mathrm{al}^{11}$ devised their new scoring system because they found that the existing formulae had limited discriminating power in paediatric patients and in adult patients undergoing wide range of procedures. The simplified scoring systems obviate laborious calculations and may reduce the scope of required detailed history taking but have demonstrated equivalent or superior discriminating power compared with more complex formulae. Despite the limitations in accuracy of PONV risk scoring systems, the use of a scoring system has been shown to have a greater discriminating power than the use of a single risk factor. Because of the accuracy and simplicity Apfel etal, Koivuranta etal and Palazzo \& Evans scoring systems were selected in our study.

In applying risk factor findings to PONV management a "decision-tree" approach has been advocated in which patients are divided into "low", "moderate", "high" or "extremely high-risk" populations based on the number, nature of the risk factors or their score on a formulae. ${ }^{12}$ Based on this risk stratification, the different treatment modalities were formulated in our study.
There have been many approaches to the treatment of PONV which includes non-pharmacological approach (acupuncture, acupressure) and pharmacological approach (anticholinergics, H1 antihistaminics, neuroleptics, 5-HT3 antagonists, prokinetic drugs \& adjuvant antiemetics). Drugs from different pharmacological group have been selected in our study to compare the efficacy of different regimens in reduction of PONV.

\section{Materials and Methods}

The study was a prospective, randomized, doubleblinded, clinical trial conducted after obtaining institutional ethical committee approval. Study was conducted in 180 patients belonging to ASA1 \& ASA2 physical status of either gender, between 18-60 years age group scheduled for elective surgery under general anesthesia of 1-4 hours duration irrespective of the type of surgery. Randomization was done using closed envelope method. Patients with increased intracranial pressure, parturients, emergency cases, patients who were on intravenous fluids and those with naso-gastric tube inserted pre-operatively were all excluded from the study.

\section{The predictors in the PONV scoring systems evaluated were:}

\begin{tabular}{|c|c|}
\hline APFEL & $\begin{array}{l}\text { a. } \text { Gender }- \text { Male }=0, \text { Female }=1 \\
\text { b. History of PONV or motion sickness- } \mathrm{No}=0, \mathrm{Yes}=1 \\
\text { c. Smoking status- } \mathrm{No}=1, \mathrm{Yes}=0 \\
\text { d. Anticipated use of post operative opoids- } \mathrm{No}=0, \mathrm{Yes}=1\end{array}$ \\
\hline KOIVURANTA & $\begin{array}{l}\text { a. Gender }- \text { Male }=0, \text { Female }=1 \\
\text { b. History of PONV- No=0, Yes }=1 \\
\text { c. Duration of Surgery }>60 \text { min- } \mathrm{No}=0, \text { Yes }=1 \\
\text { d. History of motion sickness- } \mathrm{No}=0 \text {, Yes }=1 \\
\text { e. Smoking Status- No=1, Yes }=0\end{array}$ \\
\hline PALAZZO\&EVANS & $\begin{array}{l}\text { a. Post operative opoids- } \mathrm{No}=0, \mathrm{Yes}=1 \\
\text { b. History of PONV- } \mathrm{No}=0, \mathrm{Yes}=1 \\
\text { c. Gender }- \text { Male }=0, \mathrm{Female}=1 \\
\text { d. History of motion sickness- } \mathrm{No}=0, \mathrm{Yes}=1 \\
\text { e. Female with previous PONV- } \mathrm{No}=0, \mathrm{Yes}=1\end{array}$ \\
\hline
\end{tabular}

All the patients considered for study were evaluated preoperatively and were scored for postoperative nausea and vomiting using the scoring systems. Those with the score of $0-2$ were categorized as low risk group and those with the score of 3-4 were categorised as high risk group. Written informed consent was taken from all patients. Tab. ranitidine 150 $\mathrm{mg}$ and tab. diazepam $5 \mathrm{mg}$ was administered as premedication the night before surgery. For patients in study groups, the drugs were given by an anesthesiologist who was not involved in the study. Induction of general anaesthesia was carried out using intravenous agent inj. propofol $(2-3 \mathrm{mg} / \mathrm{kg})$. Inj. vecuronium $(0.1 \mathrm{mg} / \mathrm{kg})$ or inj. atracurium $(0.5 \mathrm{mg} / \mathrm{kg})$ was used as neuro muscular blocking agents and inj. fentanyl (1-2 $\mathrm{mcg} / \mathrm{kg})$ was used to facilitate orotracheal intubation. Inj. diclofenac sodium $75 \mathrm{mg}$ was given as an added analgesic through intravenous infusion. Proper size cuffed oral endotracheal tube was inserted and mechanical ventilation initiated. Anaesthesia was maintained with $\mathrm{N} 2 \mathrm{O} 60 \%, \mathrm{O} 240 \%$ and isoflurane 0.6$1 \%$. Neuromuscular blocking agents and inj. fentanyl were supplemented intraoperatively based on the requirement. Duration of surgery, duration of anesthesia and the total intravenous fluids administered intraoperatively were all noted. Reversal of neuro muscular blockade was done with inj. neostigmine 0.05 $\mathrm{mg} / \mathrm{kg}$ along with inj. glycopyrolate $0.01 \mathrm{mg} / \mathrm{kg}$ body weight and patient was extubated. 
For patients in low risk group i.e., group O- inj. ondansetron $4 \mathrm{mg}$ was given intravenously 30 minutes before administration of reversal agent. Patients in high risk group, were further categorized into group $M$ \& group D based on the intervention planned. Patients in group $M$ received inj. ondansetron $4 \mathrm{mg}+\mathrm{inj}$. metoclopramide $10 \mathrm{mg}$ intravenously 30 minutes before administration of reversal agent. Patients in group D received inj. dexamethasone $4 \mathrm{mg}$ at induction and inj. ondansetron 4mg 30 minutes before administration of reversal agent, both the drugs administered intravenously. All the patients were observed for any retching, nausea or vomiting in the PACU and later upto 24 hours. The drugs chosen for rescue treatment in each group was from a different pharmacological group than the one used for prophylaxis and was also administered intravenously.

Group O: within 6hrs Dexamethasone 4mg, after 6hrs Ondansetron $1 \mathrm{mg}$

Group D: Propofol 20mg/ Promethazine $12.5 \mathrm{mg}$

Group M: Dexamethasone 4mg / Promethazine $12.5 \mathrm{mg}$

\section{Results}

A comparative study consisting of 180 patients with 60 patients each in group $\mathrm{O}$, group $\mathrm{D}$ and group $M$. There was no statistically significant difference in the groups in terms of age, gender, ASA physical status, weight distribution (Table 1), drugs used for induction and intraoperative intravenous fluids administered (Table 2).

All the patients considered for study were observed in PACU and upto 24 hours and we found that (as seen in figure $2 \& 3$ ) - in group O-1 patient $(1.7 \%)$ had nausea, 3 patients $(5.0 \%)$ had retching, 8 patients $(13.3 \%)$ had vomiting and 11 patients(18.3\%) required rescue treatment in PACU. In the same group, none of them had nausea or retching, 6 patients $(10.0 \%)$ had vomiting and 6 patients $(10.0 \%)$ required rescue treatment, when observed up to 24 hours. In group D - none of them had nausea, 2 patients $(3.3 \%)$ had retching, 2 patients (3.3\%) had vomiting and 4 patients $(6.7 \%)$ required rescue treatment in PACU. In the same group, none of them had nausea or retching, 2 patients $(3.3 \%)$ had vomiting and 2 patients $(3.3 \%)$ required rescue treatment, when observed up to 24 hours. In group M 2 patients $(3.3 \%)$ had nausea, 4 patients $(6.7 \%)$ had retching, 2 patients (3.3\%) had vomiting and 6 patients $(10.0 \%)$ required rescue treatment in PACU. In the same group, none of them had nausea, 2 patients (3.3\%) had retching, 4 patients $(6.7 \%)$ had vomiting and 6 patients $(10.0 \%)$ required rescue treatment, when observed upto 24 hours. The complete response (defined as no PONV and no need for a rescue antiemetic) was attained in $71.67 \%$ of patients in low risk group, $83.33 \%$ in high risk group - with $76.67 \%$ in group $\mathrm{M}$ and $90 \%$ in group D.

Receiver operator characteristics (ROC) curves (Fig. 1) were drawn for the three scores. Area under the curve (AUC) and the corresponding 95\% confidence intervals for the scores were - Apfel: 0.6154 (0.504700.72618); Koivuranta: 0.6154 (0.50470-0.72618); Palazzo \& Evans: 0.6443 (0.54096-0.74764) as seen in Table 3.

Descriptive statistical analysis has been carried out in the present study. Results on continuous measurements are presented as Mean \pm SD (Min-Max) and results on categorical measurements are presented as numbers (\%). Significance is assessed at $5 \%$ level of significance. Analysis of variance (ANOVA) has been used to find the significance of study parameters between three or more groups of patients. Bonferroni correction has been done for pairwise significance of study parameters. $2 \times 2$ Fisher exact test has been used to find the significance of study parameters on categorical scale between two groups. Kappa statistic has been used to find the significant correlation of three grading systems based on categorical agreement. ${ }^{13-15}$

The Statistical software namely SPSS 15.0, Stata 8.0, MedCalc 9.0.1 and Systat 11.0 were used for the analysis of the data. Microsoft word and excel have been used to generate graphs and tables.

Table 1: Patient characteristics

\begin{tabular}{|l|c|c|c|}
\hline & Group O & Group D & Group M \\
\hline $\begin{array}{l}\text { Age in Years } \\
\text { (Mean } \pm \text { SD) }\end{array}$ & $38.18 \pm 10.09$ & $42.17 \pm 11.34$ & $41.87 \pm 11.16$ \\
\hline Male: Female (\%) & $51.7 / 48.3$ & $40.0 / 60.0$ & $50.0 / 50.0$ \\
\hline $\begin{array}{l}\text { ASA Physical } \\
\text { status-I/II (\%) }\end{array}$ & $68.3 / 31.7$ & $56.7 / 43.3$ & $56.7 / 43.3$ \\
\hline $\begin{array}{l}\text { Weight in Kg } \\
\text { (Mean } \pm \text { SD) }\end{array}$ & $61.32 \pm 6.78$ & $64.10 \pm 9.07$ & $64.33 \pm 8.82$ \\
\hline $\begin{array}{l}\text { Duration of } \\
\text { Anesthesia (hrs) }\end{array}$ & $2.23 \pm 0.67$ & $1.95 \pm 0.40$ & $1.84 \pm 0.29$ \\
\hline $\begin{array}{l}\text { Surgery duration } \\
\text { (hrs) }\end{array}$ & $1.82 \pm 0.62$ & $1.59 \pm 0.35$ & $1.42 \pm 0.26$ \\
\hline
\end{tabular}


Table 2: Comparison of study parameters between three groups

\begin{tabular}{|l|c|c|c|c|}
\hline Study parameters & Group O & Group D & Group M & Significance \\
\hline Fentanyl $(\mu \mathrm{g} / \mathrm{kg})$ & $124.17 \pm 14.99$ & $123.00 \pm 20.54$ & $129.67 \pm 16.91$ & $\mathrm{~F}=1.398 ; \mathrm{P}=0.251(\mathrm{NS})$ \\
\hline Propofol $(\mathrm{mg} / \mathrm{kg})$ & $112.17 \pm 22.63$ & $110.33 \pm 22.05$ & $119.67 \pm 18.47$ & $\mathrm{~F}=1.670 ; \mathrm{P}=0.193(\mathrm{NS})$ \\
\hline $\begin{array}{l}\text { CRYSTALLOIDS } \\
\text { (ml/hour) }\end{array}$ & $744.05 \pm 168.47$ & $714.34 \pm 158.02$ & $743.11 \pm 149.65$ & $\mathrm{~F}=0.359 ; \mathrm{P}=0.699(\mathrm{NS})$ \\
\hline
\end{tabular}

Results are presented in Mean \pm SD

Table 3: Comparison of scores

\begin{tabular}{|l|l|l|l|l|l|}
\hline & Obs & Area & Std. Err & \multicolumn{2}{|l|}{ [95\% Conf. Interval] } \\
\hline Apfel & 120 & 0.6154 & 0.0565 & 0.50470 & 0.72618 \\
\hline Koivuranta & 120 & 0.6154 & 0.0565 & 0.50470 & 0.72618 \\
\hline $\begin{array}{l}\text { Palazzo \& } \\
\text { Evans }\end{array}$ & 120 & 0.6443 & 0.0527 & 0.54096 & 0.74764 \\
\hline
\end{tabular}

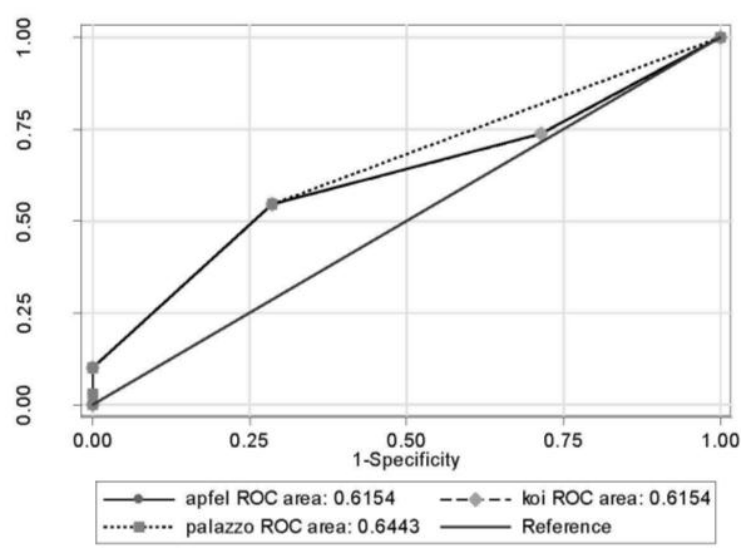

Fig. 1

\section{Discussion}

PONV is of multifactorial origin. Gold etal noted that the three most common causes for admission following day care surgery are pain, bleeding and intractable vomiting. ${ }^{1}$ The incidence of PONV after anesthesia despite the advances in antiemetic therapy in the last decade is still found to be relatively high. However, interventions to prevent PONV are not needed in the majority of the general patient population as they will not suffer these symptoms even without prophylaxis. In addition, current interventions may cause side effects and may entail substantial effort and expense. In our study - the factors that would have contributed to nausea and vomiting may be, administration of general anesthesia with inhalational anesthetics and fentanyl. Use of facemask, use of nitrous oxide may or may not have contributed to nausea and vomiting. Use of propofol might have decreased the incidence of nausea and vomiting. Adequate intraoperative hydration also might have prevented PONV. Surgeries done under general anaesthesia was chosen because of high incidence of PONV in these patients as compared to regional anaesthesia. Adequate hydration, optimum pain relief, avoidance of hypotension, adequate oxygenation, early ambulation and gentle handling of patients in the postoperative period have all found to have decreased the incidence of PONV. In our study also, all the above mentioned factors were taken care of in the study groups. As all the groups considered for study were similar in terms of patient characteristics, analgesics used, duration and type of anaesthesia, the difference in the treatment modalities were mainly based on the scoring systems. This helped us to evaluate the efficacy of the scoring systems in predicting PONV. And by comparing two different drug combinations in high risk group further helped us to evaluate the efficacy of these drugs.

Sebastien Pierre etal (2004) showed that risk score dependent antiemetic approach effectively reduces postoperative nausea and vomiting. ${ }^{16}$

In 2003, an international interdisciplinary panel of anaesthesiologists, surgeons and pharmacists led by Tong J Gan (Duke University Medical Center) developed detailed guidelines for prophylaxis and treatment of PONV. The resulting guidelines recommend - first classifying patients for the risk of PONV based on recognized risk factors and then altering any baseline risk factors that can be changed in order to lower the risk. The guidelines recommended

1. No anti emetic prophylaxis in patients with low risk of PONV. 
2. 5HT3 receptor antagonists, droperidol, dexamethasone used alone or in combination with one of the other agents is recommended as the first line antiemetic prophylaxis in patients who are at moderate risk of PONV.

3. For high risk patients, the use of triple antiemetic prophylactic therapy is recommended. Using dexamethasone at induction and 5HT3 antagonist plus droperidol at emergence.

4. When prophylactic antiemetic therapy fails, a drug from a different pharmacological group should be used for the treatment of active emesis after surgery. ${ }^{17}$

Updated guidelines for managing postoperative nausea and vomiting were announced at the 2006 annual meeting of the American Society of Anaesthesiologists (ASA) in chicago, illinois, USA and the panel recommended "prophylactic therapy with combination of drugs and three or more interventions, in patients at high risk for PONV. ${ }^{18}$ Thus, we decided to use combination of drugs in high risk group of patients. The timing of administration of antiemetic drugs and the drug selection for rescue treatment were all followed as per guidelines.

Mehernoor F Watcha suggested that, administering a repeat dose of same antiemetic to patients who have already received a prophylactic dose fails to control established PONV. So, an antiemetic from a different pharmacological group should be used as an rescue antiemetic. The same guidelines was followed in selection of drugs for rescue treatment in our study. And, it was observed that the requirement of rescue antiemetic was very less when combination prophylaxis was used. Compared to patients in group $\mathrm{M}$, patients in group D had less requirement for rescue antiemetic.

\section{Conclusion}

1. All the three scores evaluated in our study namely Apfel, Koivuranta , Palazzo \& Evans scores had moderate accuracy in predicting the risk of postoperative nausea and vomiting.

2. Ondansetron- dexamethasone combination was found to be superior to ondansetronmetoclopramide combination in high risk patients. Thus, ondansetron - dexamethasone combination was considered clinically relevant in a high risk settings.

\section{References}

1. Watcha Mehernoor F, Paul. F White. "Post operative nausea and vomiting: its etiology, treatment and prevention". Anaesthesiology 1992;77:162-84.

2. Kovac Anthony L. "Prevention and treatment of post operative nausea and vomiting” Drugs 1993;59(2):21343.

3. Kenny G N. "Risk factors for post operative nausea and vomiting". Anesthesia 1994; 49(suppl):6-10.
4. Sinclair D R, Chung F, Mezei G. Can Postoperative nausea and vomiting be predicted?. Anaesthesiology 1999; 91:109-18.

5. Koivuranta M,Laara E, Snare L, Alahuhta S. A survey of Postoperative nausea and vomiting. Anaesthesia 1997;52:443-9.

6. Lerman J. "Surgical and patient factors involved in post operative nausea and vomiting". Br J Anaesth 1992; 69:24-45.

7. Apfel C C, Grein C A, Haubitz I, etal. A risk score to predict the probability of post operative vomiting in adults. Acta Anaesthesiol Scand 1998;42:495-501.

8. Apfel CC, Laara E, Koivuranta M, etal. A simplified risk score for predicting post operative nausea and vomiting: conclusions from cross-validations between two centres. Anaesthesiology 1999;91:693-700.

9. Eberhart L H, Geldner G, Kranke P,etal. The development and validation of a risk score to predict the probability of post operative vomiting in paediatric patients. Anesth Analg 2004;99:1630-7.

10. Eberhart LH, Morin A M, Guber D ,etal. Applicability of risk scores for Postoperative nausea and vomiting in adults to paediatric patients. Br J Anaesth 2004;93:38692.

11. Vanden Bosch J E, Moons K G, Bonsel G J, Kalkman C $\mathrm{J}$. Does measurement of preoperative anxiety have added value for predicting post operative nausea and vomiting? Anaesth Analg 2005; 100:1525-32.

12. Gan T J. "Post operative nausea and vomiting- can it be eliminated?" JAMA 2002;287:1233-6.

13. Bernard Rosner (2000): Fundamentals of Biostatistics, $5^{\text {th }}$ Edition, Duxbury, p80-240.

14. M. Venkataswamy Reddy (2002): Statistics for Mental Health Care Research, NIMHANS publication, India, p108-14.

15. Sunder Rao P S S , Richard J: An Introduction to Biostatistics - A manual for students in health sciences , New Delhi:p 86-160.

16. Sebastien Pierre, Gaelle Corno etal. "A risk score dependent antiemetic approach effectively reduces post operative nausea and vomiting - a continuous quality improvement initiative". Can J Anaesth 2004;51:320-5.

17. Elaine Long. Special report: Stemming The Tide: New PONV guidelines; Digestive health online content, May 19, 2003(Cited on January 15, 2007). http:// digestive healthcentersonline.mediwire.com/main/default.aspx.

18. New guidelines issued for PONV 2005-2006 (Cited on November 22, 2006) http://www.anesthesianow.com/news 